\title{
DÜBLIN
}

Technological University Dublin

ARROW@TU Dublin

\section{Nonlinear Control Methods for Single-Ended Primary-Inductor Power Converters}

\author{
Samet Biricik \\ European University of Lefke (Cyprus) \\ Tuan Ngo \\ University of Austin, Texas \\ Hasan Komurcugil \\ Eastern Mediterranean University - Turkey
}

See next page for additional authors

Follow this and additional works at: https://arrow.tudublin.ie/engscheleart

Part of the Electrical and Computer Engineering Commons

\section{Recommended Citation}

Biricik, S., Ngo, T. , Komurcugil, H. \& Basu, M. (2017). Nonlinear control methods for single-ended primaryinductor power converters. Proceedings IECON 2017: 43rd Annual Conference of the IEEE Industrial Electronics Society, Beijing, October 29 to November 1. doi:10.1109/IECON.2017.8216227

This Conference Paper is brought to you for free and open access by the School of Electrical and Electronic Engineering at ARROW@TU Dublin. It has been accepted for inclusion in Conference papers by an authorized administrator of ARROW@TU Dublin. For more information, please contact arrow.admin@tudublin.ie, aisling.coyne@tudublin.ie,gerard.connolly@tudublin.ie.

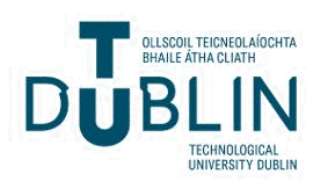




\section{Authors}

Samet Biricik, Tuan Ngo, Hasan Komurcugil, and Malabika Basu

This conference paper is available at ARROW@TU Dublin: https://arrow.tudublin.ie/engscheleart/274 


\title{
Nonlinear Control Methods for Single-Ended Primary-Inductor Power Converters
}

\author{
Samet Biricik ${ }^{1,4}$, Tuan $\mathrm{Ngo}^{2}$, Hasan Komurcugil ${ }^{3}$, and Malabika Basu ${ }^{4}$ \\ ${ }^{1}$ Department of Electrical \& Electronic Eng., European University of Lefke, Via Mersin 10, Turkey. \\ ${ }^{2}$ Department of Electrical and Computer Engineering, The University of Texas at Austin, TX, USA. \\ ${ }^{3}$ Department of Computer Engineering, Eastern Mediterranean University,Via Mersin 10, Turkey. \\ ${ }^{4}$ School of Electrical \& Electronic Engineering, Dublin Institute of Technology (DIT), Dublin, Ireland. \\ \{samet@biricikelektrik.com,ngotuan@utexas.edu, hasan.komurcugil@emu.edu.tr, malabika.basu@dit.it\}
}

\begin{abstract}
This paper investigates nonlinear control methods for single-ended primary-inductor converters (SEPIC). The fastswitching and average models show the converter nonlinearity in terms of inductor currents, capacitor voltages, and the switching duty cycle. The control law intuitively should be nonlinear to drive and guarantee the system stability. Two different control laws based on the passivity and back-stepping technique are examined and designed to have asymptotically global stability in the system. Unlike the passivity method which regulates the duty cycle directly, the back-stepping method adjusts the switching duty by a driver integrator/low pass filter system. The simulation results have shown the benefits from the passivity control law over the back-stepping one. Moreover, an observer is introduced in order to reduce the number of voltage and current sensors for the control system. The nonlinear control law is thus a combination of the measured signal and the estimated ones. Simulation results are also presented to verify the effectiveness of the observer in the control system.
\end{abstract}

Keywords- DC-DC power converters, Nonlinear control systems, Observers, Feedback, State estimation.

\section{INTRODUCTION}

The single-ended primary-inductor converter (SEPIC) has offered great benefits for power conversion since it can generate a wide range of output voltage. A SEPIC converter is able to operate in a buck mode or a boost mode depending on the duty cycle value. In other words, the input impedance of a SEPIC converter can be changed by regulating the duty cycle. This property makes the SEPIC converter as an excellent candidate for PV applications because it can match the entire IV characteristics curve [1].

The SEPIC converter has been modelled and controlled by different methods described in [2] and [3]. The converter can achieve maximum power point tracking (MPPT) properly. However, those control techniques are typically based on the linearization at operating points. The converter system is thus locally stable with limited variations on the load demand side. Several approaches using nonlinear control have been proposed to improve the system stability. The most common technique is utilizing a sliding mode control as in [4]-[6]. This method requires less inductor current, but results in larger ripples in voltages and currents compared to the passivitybased control as concluded in [7].

One major disadvantage of nonlinear control methods is the requirement of full-state feedback. In other words, four sensors need to be installed in order to measure voltages and currents across capacitors and inductors, respectively.

Our motivation in this paper is to present the nonlinear model of SEPIC converters in detail and investigate different control laws. In [7], the model is presented with PV system dynamics. However, this is unnecessary since the capacitor in the solar panel side is typically large and its dynamic performance is much slower compared to that of the power converter. More importantly, adding the solar panel dynamics makes the controller more complicated. Our target is to model the SEPIC converter precisely in order to find the nonlinearity relation between voltages, currents, and the switching duty cycle. The second step is to investigate different nonlinear control laws based on our model and Lyapunov's energy storage function to achieve asymptotic stability for a wide range of load variations. Our final target is to introduce an observer for the nonlinear passivity-based control system in order to reduce the number of voltage and current sensors in the converter.

This paper begins in Section II by modelling the SEPIC converter from the switching states. Two different nonlinear control methods are introduced based on the passivity and back-stepping approaches. An observer is then introduced in order to reduce the sensors for the converter control system. Section III presents simulation results for both methods and also the system responses with the observer implementation. Section IV provides several important conclusions for the nonlinear controllers in SEPIC converters. 


\section{THE SEPIC CONVERTER MODELING AND NONLINEAR CONTROL METHODS}

This section investigates the state-space model of a SEPIC converter shown in Fig. 1. The fast switching and average models are derived. The two different approaches based Lyapunov's function are then introduced to find the nonlinear control laws. In the final subsection, an observer is examined to reduce the number of sensors for converters.

\section{A. The SEPIC Converter Model}

From the circuit diagram and KVL (KCL), the states corresponding to on/off of switch are defined. The fast switching model for the SEPIC converter is based on these states [8]. After that, the average model can be easily derived and then used for control law calculations.

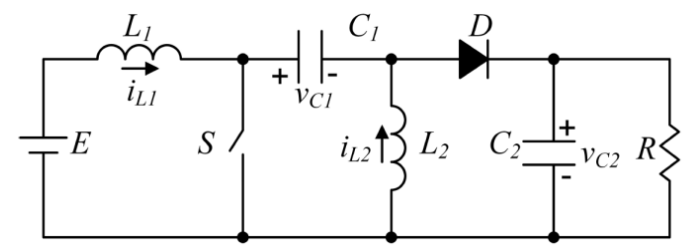

Fig. 1. A typical SEPIC converter configuration.

When switch is on, the inductor $L_{1}$ is energized from the source while the inductor $L_{2}$ discharges capacitor $C_{1}$. At the same time, the capacitor $C_{2}$ provides power to the load. The on-state of converter can be expressed as

$$
\begin{gathered}
L_{1} \frac{d i_{L 1}}{d t}=E, L_{2} \frac{d i_{L 2}}{d t}=v_{C 1} \\
C_{1} \frac{d v_{C 1}}{d t}=-i_{L 2}, C_{2} \frac{d v_{C 2}}{d t}=-\frac{v_{C 2}}{R}
\end{gathered}
$$

When switch is off, the two inductors are de-energized through the capacitors and the load. The off-state is mathematically described by differential equations given below

$$
\begin{aligned}
& L_{1} \frac{d i_{L 1}}{d t}=E-v_{C 1}-v_{C 2}, L_{2} \frac{d i_{L 2}}{d t}=-v_{C 2} \\
& C_{1} \frac{d v_{C 1}}{d t}=i_{L 1}, C_{2} \frac{d v_{C 2}}{d t}=i_{L 1}+i_{L 2}-\frac{v_{C 2}}{R}
\end{aligned}
$$

Denoting $x_{1}=i_{L 1}, x_{2}=v_{C 1}, x_{3}=i_{L 2}, x_{4}=v_{C 2}$, and $q$ as switching function, the fast switching model is given by

$$
\begin{aligned}
& L_{1} \dot{x_{1}}=E-(1-q)\left(x_{2}+x_{4}\right) \\
& C_{1} \dot{x_{2}}=(1-q) x_{1}+q x_{3} \\
& L_{2} \dot{x_{3}}=q x_{2}-(1-q) x_{4} \\
& C_{2} \dot{x_{4}}=(1-q)\left(x_{1}+x_{3}\right)-\frac{x_{4}}{R}
\end{aligned}
$$

The average model with $d$ as duty cycle can be derived directly from the above fast-switching model as follows

$$
\begin{aligned}
& \dot{x_{1}}=\frac{E}{L_{1}}-(1-d)\left(\frac{x_{2}+x_{4}}{L_{1}}\right) \\
& \dot{x_{2}}=(1-d) \frac{x_{1}}{C_{1}}+d \frac{x_{3}}{C_{1}}
\end{aligned}
$$

$$
\begin{aligned}
& \dot{x_{3}}=d \frac{x_{2}}{L_{2}}-(1-d) \frac{x_{4}}{L_{2}} \\
& \dot{x_{4}}=(1-d)\left(\frac{x_{1}+x_{3}}{C_{2}}\right)-\frac{x_{4}}{C_{2} R}
\end{aligned}
$$

The equilibrium point for the SEPIC converter at an operating condition with duty cycle $D$ is: $x_{1 e}=\frac{E}{R}\left(\frac{D}{1-D}\right)^{2}, x_{2 e}=E$, $x_{3 e}=\frac{E}{R}\left(\frac{D}{1-D}\right)$, and $x_{4 e}=E\left(\frac{D}{1-D}\right)$. If we define $e_{1}=x_{1}-x_{1 e}$, $e_{2}=x_{2}-x_{2 e}, e_{3}=x_{3}-x_{3 e}, e_{4}=x_{4}-x_{4 e}$, and $u=d-D$, then the system model in (4) can be represented as

$$
\begin{aligned}
\dot{e}=f(e)+g(e) u= & {\left[\begin{array}{cccc}
0 & \frac{D-1}{L_{1}} & 0 & \frac{D-1}{L_{1}} \\
\frac{D-1}{C_{1}} & 0 & \frac{-D}{C_{1}} & 0 \\
0 & \frac{D}{L_{2}} & 0 & \frac{D-1}{L_{2}} \\
\frac{D-1}{C_{2}} & 0 & \frac{1-D}{C_{2}} & \frac{-1}{C_{2} R}
\end{array}\right] } \\
& +\left[\begin{array}{c}
\frac{1}{L_{1}}\left(e_{2}+e_{4}+\frac{E}{1-D}\right) \\
\frac{-1}{C_{1}}\left(e_{1}+e_{3}+\frac{E}{R} \frac{D}{(1-D)^{2}}\right. \\
\frac{1}{L_{2}}\left(e_{2}+e_{4}+\frac{E}{1-D}\right) \\
\frac{-1}{C_{2}}\left(e_{1}+e_{3}+\frac{E}{R} \frac{D}{(1-D)^{2}}\right.
\end{array}\right]
\end{aligned}
$$

where $e=\left[e_{1} e_{2} e_{3} e_{4}\right]^{T}$ are the state errors. The error model is a combination of a linear system $f(e)$ and a nonlinear system $g(e) u$.

It is worthwhile to notice that the system $\dot{e}=f(e)$ is stable. Consider the radial unbounded energy storage function,

$$
V(e)=\frac{1}{2} L_{1} e_{1}^{2}+\frac{1}{2} C_{1} e_{2}^{2}+\frac{1}{2} L_{2} e_{3}^{2}+\frac{1}{2} C_{2} e_{4}^{2}
$$

then

$$
\begin{aligned}
& \dot{V}(e)=L_{1} e_{1} \dot{e_{1}}+C_{1} e_{2} \dot{e_{2}}+L_{2} e_{3} \dot{e_{3}}+C_{2} e_{4} \dot{e_{4}} \\
& =\left[\begin{array}{llll}
L_{1} e_{1} & C_{1} e_{2} & L_{2} e_{3} & C_{2} e_{4}
\end{array}\right] f(e) \\
& \left(-\frac{1}{R}\right) e_{4}^{2} \leq 0
\end{aligned}
$$

thus the system is globally asymptotically stable (GAS). The duty cycle variation $u$ is treated as input signal to stabilize system in (5). The following section introduces different nonlinear control methods.

\section{B. Nonlinear Control Methods}

The state-space model of errors is rewritten as

$$
e=f(e)+g(e) u
$$

where $f(e)$ and $g(e)$ are functions of linear state combinations. The control signal $u$ is designed in a way that the closed-loop system in (8) is asymptotically stable. The two control methods: passivity and back-stepping are investigated

1) Passivity Control: Consider again the same energy storage function $V(e)$ in (6) for system described in (8). Then,

$$
\dot{V}(e)=\left[\begin{array}{llll}
L_{1} e_{1} & C_{1} e_{2} & L_{2} e_{3} & C_{2} e_{4}
\end{array}\right][f(e)+g(e) u]
$$




$$
\begin{gathered}
=\frac{e_{4}^{2}}{R}+\frac{E}{1-D}\left[\left(e_{1}+e_{3}\right)-\frac{D}{1-D}\left(\frac{e_{2}+e_{4}}{R}\right)\right] u \\
\quad \leq \frac{E}{1-D}\left[\left(e_{1}+e_{3}\right)-\frac{D}{1-D}\left(\frac{e_{2}+e_{4}}{R}\right)\right]
\end{gathered}
$$

If the output signal is selected as $y=\frac{E}{1-D}\left[\left(e_{1}+e_{3}\right)-\right.$ $\left.\frac{D}{1-D}\left(\frac{e_{2}+e_{4}}{R}\right)\right]$, the system is passive because $\dot{V}(e) \leq y^{T} u$ and is asymptotically stable with the control input

$$
u=-k y=-k \frac{E}{1-D}\left[\left(e_{1}+e_{3}\right)-\frac{D}{1-D}\left(\frac{e_{2}+e_{4}}{R}\right)\right]
$$

where $k$ is a positive constant. It is interesting to see that the control signal $u$ is established from the power variations between inductors and capacitors. The duty cycle control signal is now can be calculated from the real states as follows

$$
\begin{gathered}
d=D+u \\
=D-k \frac{E}{1-D}\left[\left(x_{1}+x_{3}\right)-\frac{D}{1-D}\left(\frac{x_{2}+x_{3}}{R}\right)\right]
\end{gathered}
$$

2) Back-stepping Control: The control signal can be designed using back-stepping technique. Instead of direct calculation from states, the control signal is coming from a driver system, for example an integrator or a linear filter [9]. The dynamic system is (8) is modified as

$$
\dot{e}=f(e)+g(e) u \quad \dot{u}=v
$$

The dynamic system for (12) is described as in Fig. 2. The duty cycle $u$ is driven by input signal $u$ through an integrator. The nonlinear control law can established based on full-state feedback of $e$ and $u$.

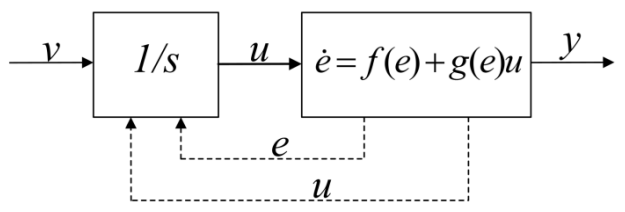

Fig. 2. A state-space model for the back-stepping control.

The above system can be asymptotically stable with the composite energy storage function, $V(e, u)=(1 / 2) e^{2}+$ $(1 / 2) u^{2}$, by the following control law

$$
v=-\frac{E}{1-D}\left[\left(x_{1}+x_{3}\right)-\frac{D}{1-D}\left(\frac{x_{2}+x_{4}}{R}\right)\right]-k(d-D)
$$

where $k$ is again a positive constant.

\section{Reduced Observers}

From the control signal representation in (11) and (13), the full-state signals are required for the control law. Thus, two voltage and two current sensors are needed to measure states and this increases physicals size and cost of the system in practice. Instead, an observer can be constructed with fewer sensors to establish the control signal. Assuming only the output voltage measurement is available for the system, then $y=C e=\left[\begin{array}{llll}0 & 0 & 0 & 1\end{array}\right] e=e_{4}$. In this case, an observer for the system with passivity control law is considered. The statespace model for this observer is given by [10]

$\dot{\hat{e}}=f(\hat{e})+g(\hat{e}) u+L(y-C \hat{e})=A \hat{e}+g(\hat{e}) u+$

$L\left(e_{4}-\widehat{e_{4}}\right)$

where $A$ is a constant matrix from (5), $\hat{e}$ are estimated states, and $L=\left[\begin{array}{llll}l_{1} & l_{2} & l_{3} & l_{4}\end{array}\right]^{T}$ are observer gains. Since $g(\hat{e})$ is a linear combination of states, it can be assumed that this estimation is able to cancel the corresponding part in physical model for simplicity. The pair $(A, C)$ is observable because the observer matrix rank is four and it is thus simple to design gain $L$ by pole placements. It is degraded to two if the inductors are same values $L_{1}=L_{2}$ and the duty cycle is $D=0.5$. This case should be noticed for observer gain values is presented in Section III.

\section{SimUlation RESUlts}

The nonlinear control methods and observer are employed in a SEPIC converter. The parameters used in this study are $E=24 \mathrm{~V}, L_{1}=700 \mu \mathrm{H}, L_{2}=700 \mu \mathrm{H}, C_{l}=50 \mu \mathrm{F}, C_{2}=10 \mu \mathrm{F}, R=20$ $\Omega, f_{s w}=100 \mathrm{kHz}$ Several cases have been simulated to verify the nonlinear control methods. First, the converter system with passivity controller is presented without any switching action in the model. Then, the results from two designed controllers with switching effects are compared. The last case study is the implemented observer results.

\section{A. The Passivity Controller without Switching Action}

In this case, the passivity controller is tested with gain $\mathrm{k}=0.00015$ and the results are shown in Fig. 3. Since the voltage across capacitor $C_{1}$ is always constant at $v_{C l}=E$, its waveform is thus not presented to save space. The waveforms of currents through inductors, Fig. 3 (a) and output voltage, Fig. 3 (b), indicates that the designed controller performs well after a short transient duration when the reference output is changed from $24 \mathrm{~V}$ to $16 \mathrm{~V}$ and $56 \mathrm{~V}$. Since there is no switching action in the model, the voltage and current waveforms are flat and having no ripples.

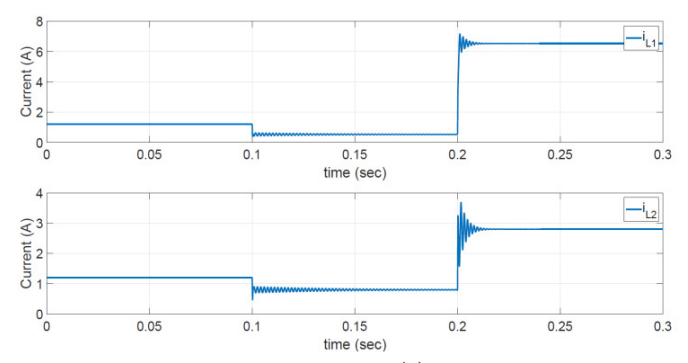

(a)

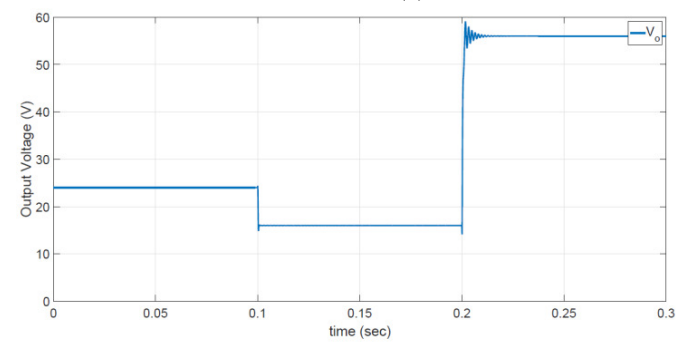

(b)

Fig. 3. Passivity control : (a) inductors, and (b) output voltage waveforms. 


\section{B. Comparisons between two Designed Control Laws}

The two controllers are implemented in the converter and compared. The gains for each controller are set at $k_{\text {Pass }}=0.00015$ and $k_{\text {Back }}=0.00015$. The converter is simulated with two cases of buck-mode $(16 \mathrm{~V})$ and boost-mode $(36 \mathrm{~V})$ corresponding to Fig. 4(a) and Fig. 4(b), respectively. For convenience of comparison, waveforms from the backstepping method are plotted inversely. Due to the switching effects, the current and voltage have ripples around the operation points. It is noticeable that waveforms from the passivity method have less ripples and smoother, especially in the buck-mode. This can be explained by the indirect control law in the back-stepping method.
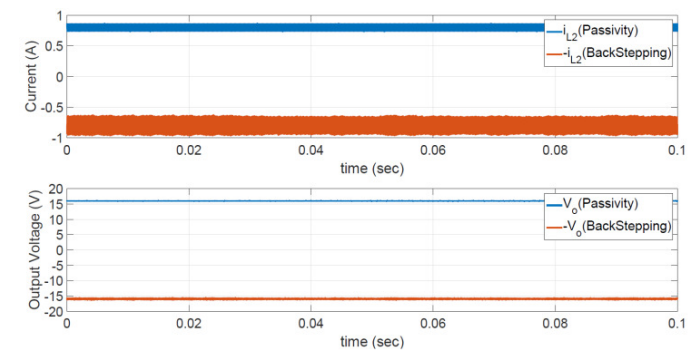

(a)
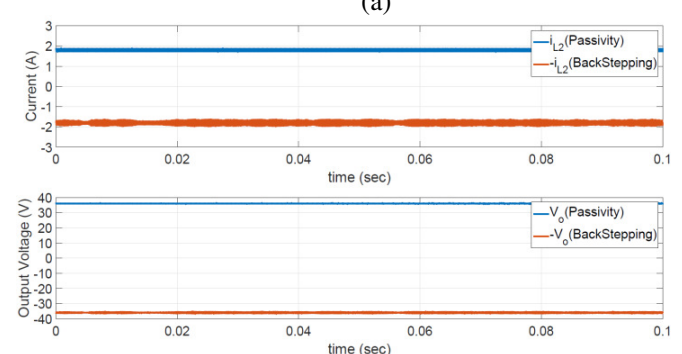

(b)

Fig. 4. Current and voltage waveforms in (a) buck-mode, and (b) boost-mode.
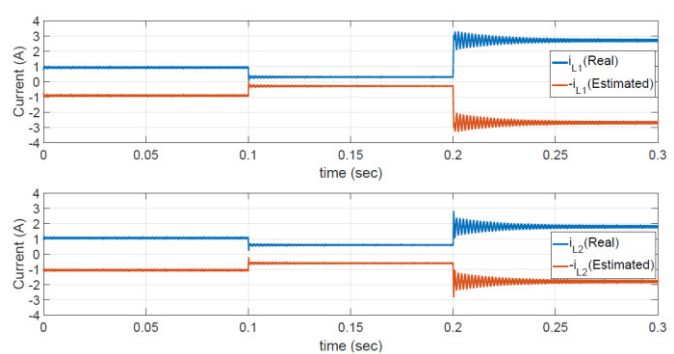

(a)

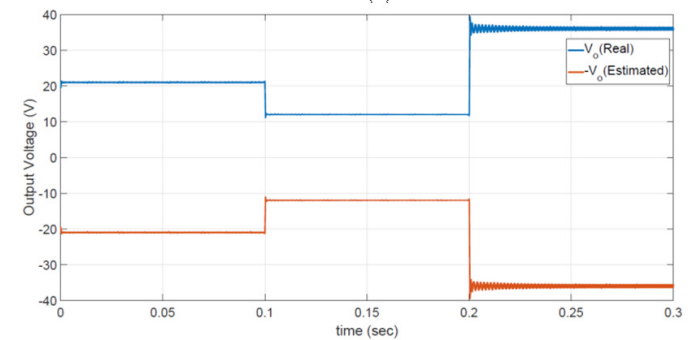

(b)

Fig. 5. Real and estimated waveforms of a) currents, and b) output voltages.

\section{The Designed Observer for Passivity Control Method}

As mentioned in the previous section, an observer is constructed, based on the pole placement method, for a SEPIC converter to reduce the number of sensors. The states from this observer are combined with the measured output voltage signal to form the control law to reduce required number of sensors from 4 to 1 (only output voltage is measured). The observer gains are selected $L=[-2229,-329,395,-179]^{T}$ to guarantee the poles of the closed-loop system on the left half plane. For comparison, the switching effects are not included and the estimated states are plotted inversely as shown in Fig. 5. It is clear that the voltage and current waveforms of real and estimated states are reflections of each other. In other words, the estimated values from the observer are almost the same as those real values. This verifies the effectiveness of the designed controller and observer for SEPIC converters.

\section{CONCLUSIONS}

In this paper, two nonlinear control methods based on passivity and back-stepping technique are introduced for SEPIC converters. The controllers require full-state feedback to stabilize the converter system at an operating point. Simulation results shows the passivity control law outcomes less ripples on voltage and current waveforms since it controls the converter duty cycle directly. An observer is also designed to reduce the sensor numbers, while effectively tracking the physical model states. This verifies that the nonlinear control law and the observer can be used to regulate the output voltage of SEPIC converters.

\section{REFERENCES}

[1] A. Kwasinski, Lecture notes in Power electronics. The University of Texas at Austin, Spring 2014.

[2] S. J. Chiang, H. J. Shieh, and M. C. Chen, "Modeling and control of pvcharger system with sepic converter," IEEE Trans. Ind. Electron., vol. 56, no. 11, pp. 4344-4353, Nov 2009.

[3] A. R. Kashyap, R. Ahmadi, and J. W. Kimball, "Input voltage control of sepic for maximum power point tracking," in Power and Energy Conference at Illinois (PECI), IEEE, Feb 2013, pp. 30-35.

[4] A. Kavitha, G. Indira, and G. Uma, "Analysis and control of chaos in sepic dc-dc converter using sliding mode control," in Industry Applications Society Annual Meeting, 2008, Oct 2008, pp. 1-6.

[5] E. Mamarelis, G. Petrone, and G. Spagnuolo, "Design of a slidingmodecontrolled sepic for pv mppt applications," IEEE Trans. Ind. Electron., vol. 61, no. 7, pp. 3387-3398, July 2014.

[6] S. B. Wang, Y. Zhou, H. H. C. Iu, and J. N. Chen, "Complex phenomena in sepic converter based on sliding mode control," IEEE Int. Symposium on Circuits and Systems, May 2007, pp. 2407-2410.

[7] J. E. Salazar-Duque, E. I. Ortiz-Rivera, and J. Gonzalez-Llorente, "Analysis and non-linear control of sepic dc-dc converter in photovoltaic systems," in Power Electronics and Power Quality Applications (PEPQA), 2015 IEEE Workshop on, June 2015, pp. 1-6.

[8] R. W. Erickson and D. Maksimovic, Fundamentals of Power Electronics.Springer, 2001.

[9] K. H. Khalil, Nonlinear Systems. Pearson, 2001

[10] F. Golnaraghi and B. C. Kuo, Automatic Control Systems. Wiley, 2009 